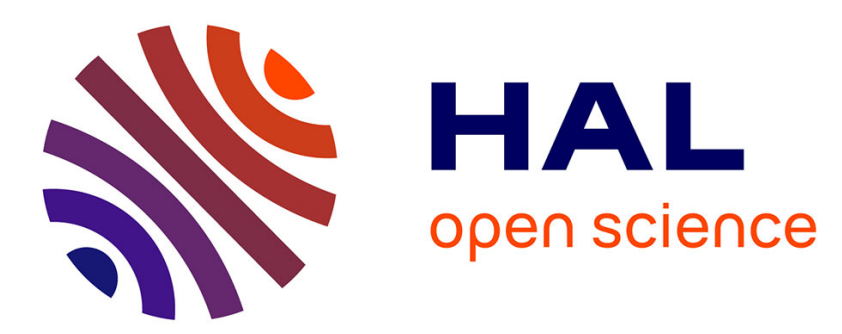

\title{
Field Electron Emission Spectroscopy of YBa2Cu3O6.9 Single Crystals Above and Below Superconducting Transition Temperature
}

S. Ivanov, S. Shkuratov

\section{- To cite this version:}

S. Ivanov, S. Shkuratov. Field Electron Emission Spectroscopy of YBa2Cu3O6.9 Single Crystals Above and Below Superconducting Transition Temperature. Journal de Physique IV Proceedings, 1996, 06 (C5), pp.C5-135-C5-140. 10.1051/jp4:1996522 . jpa-00254401

\section{HAL Id: jpa-00254401 https://hal.science/jpa-00254401}

Submitted on 1 Jan 1996

HAL is a multi-disciplinary open access archive for the deposit and dissemination of scientific research documents, whether they are published or not. The documents may come from teaching and research institutions in France or abroad, or from public or private research centers.
L'archive ouverte pluridisciplinaire HAL, est destinée au dépôt et à la diffusion de documents scientifiques de niveau recherche, publiés ou non, émanant des établissements d'enseignement et de recherche français ou étrangers, des laboratoires publics ou privés. 


\title{
Field Electron Emission Spectroscopy of $\mathrm{YBa}_{2} \mathrm{Cu}_{3} \mathrm{O}_{6.9}$ Single Crystals Above and Below Superconducting Transition Temperature*
}

\author{
S.N. Ivanov and S.I. Shkuratov \\ Institute of Electrophysics, Russian Academy of Sciences, 34 Komsomolskaya Str., Ekaterinburg 620049, \\ Russia
}

\begin{abstract}
An experimental investigation has been made of the total energy distribution of electrons emitted from the surfaces, purified by field evaporation, of $\mathrm{YBa}_{2} \mathrm{Cu}_{3} \mathrm{O}_{6.9}$ single crystals oriented in the [100] direction at temperatures above and below superconducting transition temperature. Field electron emission spectroscopic experiments carried out at $75 \mathrm{~K}$ visualized the superconducting energy gap at the Fermi-edge of the spectra. The number of electrons in the energy interval inside the gap decreases to the zero level. The double value of the superconducting energy gap for crystallographic direction [100] measured at temperature $75 \mathrm{~K}$ has the width $30 \pm 5 \mathrm{meV}$.
\end{abstract}

\section{INTRODUCTION}

The transition of the superconductor from the normal to the superconducting state is accompanied by the emergence of a narrow forbidding band - superconducting energy gap in the electronic energy spectrum of materials. The width of the superconducting energy gap is one of the most important characteristics of the superconductor. The theoretical fundamental of using field electron emission spectroscopy (FEES) for determination of the gap width worked out fairly long ago [1,2]. However, the small size of the gap in case of classical superconductors and limited energy resolution of existing analyzers [3] have not yet made it possible to use FEES for measuring gap size. Investigations of $\mathrm{Bi}$-superconductors at temperatures above and below superconducting transition temperature $\left(\mathrm{T}_{\mathrm{c}}\right)$ using FEES conducted by Ernst et al [4] have shown that in case of high temperature superconducting (HTSC) materials the use of this method is more promising.

Field emission techniques offer some advantages over other methods for the investigation of crystalline and electronic structures, namely, high spatial resolution, observation of the state of the object under investigation, and contactlessness [3, 5-7]. Field ion microscopy (FIM) of a HTSC specimen allows one to observe a surface with atomic resolution [8-11] and to analyze the bulk atomic structure by means of controlled field evaporation of the surface atom layers of the material itself. Field electron emission microscopy (FEM) and spectroscopy allow one to obtain information about the electronic properties of the specimen surface cleaned by field evaporation [12-16].

Field electron emission spectroscopy of $\mathrm{YBa}_{2} \mathrm{Cu}_{3} \mathrm{O}_{6.9}$ single crystals at temperatures above and below superconducting transition temperature $T_{c}$, is a continuation of a series of our investigation of the electronic structure and emissive properties of atomically clean surfaces of these compound using field emission techniques [12-16]. Field emission investigations of this compound at temperatures above the superconducting transition temperature $T_{c}$ have shown similar features of field emission from HTSC and metals [12-17]. Field electron emission spectroscopy of HTSC single crystals at temperatures below the superconducting transition temperature $T_{c}$ would make it possible to obtain information on

\footnotetext{
* A part of expenses incurred during this work has been covered by one of the authors (S.I. Shkuratov).
} 
the electron energy distribution in superconducting state.

\section{EXPERIMENTAL PROCEDURES}

The investigations were carried out in a specially designed set-up $[14,18,19]$ consisting of a dispersion-type field electron emission spectrometer [20] combined with a field ion microscope and field electron emission microscope. An ultra high vacuum (UHV) chamber is equipped with a vacuum lock to mount a specimen without breaking vacuum in the main chamber. The best attainable vacuum for this system is $5 \times 10^{-11}$ Torr. Estimation of the spectrometer resolution by using the Young and Kuyatt criterion [21] (the $10-90 \%$ level of the energy distribution leading edge of tungsten) gives 30 $\mathrm{meV}$. The transmission energy of the analyzer dispersion element is variable in steps of $5 \mathrm{meV}$. The experiments were carried out at $75 \mathrm{~K}$ (cooling agent - liquid helium), $115 \mathrm{~K}$ (cooling agent - liquid nitrogen) and $300 \mathrm{~K}$.

$\mathrm{YBa}_{2} \mathrm{Cu}_{3} \mathrm{O}_{6.9}$ single crystals were grown by the solution - in - melt method [22]. The single crystal dimensions were $2 \times 2 \mathrm{~mm}^{2}$ and 0.03-0.1 $\mathrm{mm}$ in thickness. $\mathrm{X}$ - ray and metallographic analyses did not show any inclusions on the surface or in the bulk of single crystals. Lattice parameters measured in various parts of the single crystals showed the same values $(a=0.3817, b=0.3886, c=1.1684 \mathrm{~nm})$. The superconductivity transition temperature $\mathrm{T}_{\mathrm{c}}$ measured by inductive method was equal to $92 \mathrm{~K}$ $\left(\Delta \mathrm{T}_{\mathrm{c}}=0.1 \mathrm{~K}\right)$. The tip specimens were prepared by a specially developed technique [23]: soldering of HTSC specimens to a metallic needle substrate. This method ensures a low electric resistivity and low noise of contact between HTSC and metallic substrate.

Field ion microscopy of HTSC specimens was the first stage of spectroscopic investigation and made it possible to prepare in situ an atomically smooth surface by field evaporation of atoms from the more protruding areas at the apex of the tip specimen and visualize it with a separate atom resolution. Molecular nitrogen [11] was used as an imaging gas. After evacuation of the imaging gas down to $\mathrm{P}=1 \times 10^{-10}$ Torr, the tip surface was cleaned by a controlled field evaporation of the atomic layers of the material, which excluded any chemical, radiation or thermal effect on the object under investigation. The next stage in the investigation of the HTSC specimen was the field electron emission microscopy and field electron emission spectroscopy. The surface was cleaned by field evaporation directly before each FEES and FEM measurement.

\section{RESULTS AND DISCUSSION}

Field ion images of $\mathrm{YBa}_{2} \mathrm{Cu}_{3} \mathrm{O}_{6.9}$ showed a ring pattern typical of a perfect surfaces (Fig. 1a). The analysis of the bulk atomic structure by examing the specimen surface during the process of consequent removal of material atoms by an electric field showed the absence of defects in the crystalline structure of the investigated specimens. A comparative analysis of numerically simulated $[24,25]$ and observed ion micropictures allowed one to determine the crystallographic orientation of $\mathrm{YBa}_{2} \mathrm{Cu}_{3} \mathrm{O}_{6.9}$ specimens as [100] (or [010]).

FEM of field evaporated cleaned surfaces of $\mathrm{YBa}_{2} \mathrm{Cu}_{3} \mathrm{O}_{6.9}$ single crystal specimen at temperatures $300 \mathrm{~K}$ and $115 \mathrm{~K}$ are presented in fig. $1 \mathrm{~b}-\mathrm{c}$. The comparative analysis of different-temperature electron emission microimages of atomically smooth field evaporated cleaned surface $\mathrm{YBa}_{2} \mathrm{Cu}_{3} \mathrm{O}_{6.9}$ specimens shows that neither the form not the area of emission regions changes during cooling at the same high voltage applied to the emitter. For semiconductor tip specimens ( $\mathrm{Si}$, Ge, etc.), cooling leads to 

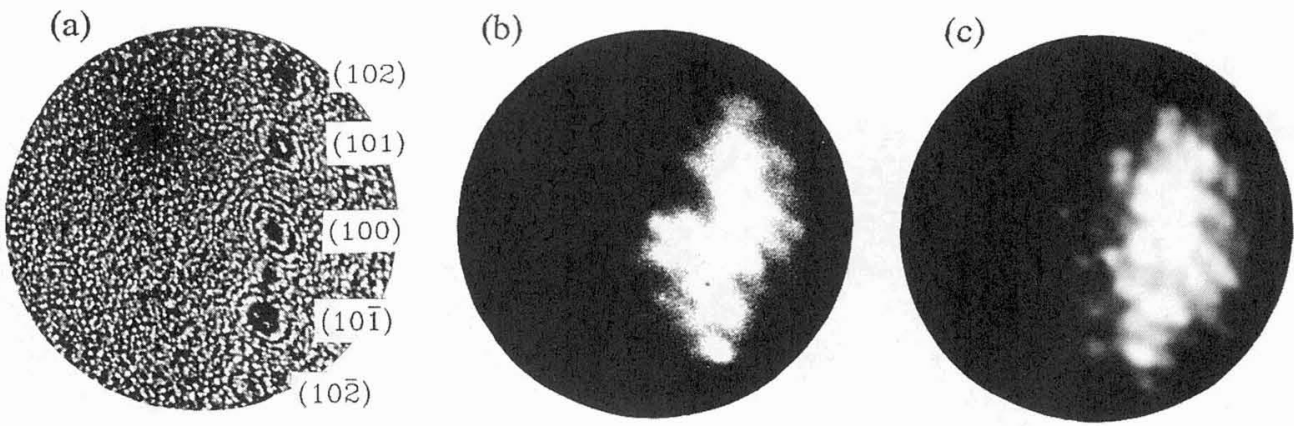

Fig.1. Field emission microscopy of $\mathrm{YBa}_{2} \mathrm{Cu}_{3} \mathrm{O}_{6.9}$ single crystal specimen at different temperatures. (a) Field ion microimage with Miller indices of morphological development faces $\left(P=1 \times 10^{-5}\right.$ Torr, $U=+9.18 \mathrm{kV}$, nitrogen as imaging gas, $T=115 \mathrm{~K})$. (b,c) Field electron emission microimages of field evaporated cleaned surface $\left(\mathrm{P}=1 \times 10^{-10}\right.$ Torr, $\mathrm{U}=-2.2 \mathrm{kV})$ at $115 \mathrm{~K}(\mathrm{~b})$ and $300 \mathrm{~K}(\mathrm{c})$.

reduction of the emission region owing to the decrease of density of charge carriers and the penetration of the electric field deeper into the subsurface layer of the specimens [26]. Similarly to metals, current-voltage characteristics (CVC's) of field electron emission currents from field evaporated cleaned surfaces of $\mathrm{YBa}_{2} \mathrm{Cu}_{3} \mathrm{O}_{6.9}$ emitters on the Fowler-Nordheim coordinates have no breaks (fig.2). Measurements of CVC's at different temperatures showed that an emission current does not changes with cooling. It is also a typical metallic behaviour of the material [26]. The work function was calculated from the slop of the Fowler-Nordheim plot is $\phi \cong 6.1 \mathrm{eV}(\mathrm{T}=115 \mathrm{~K}$, average data for seven specimens).

Figure 3 shows total-energy distribution of field emitted electrons (TED) from field evaporated cleaned surface of $\mathrm{YBa}_{2} \mathrm{Cu}_{3} \mathrm{O}_{6.9}$ single crystal specimen at $300 \mathrm{~K}$, and TED from the same specimen at $115 \mathrm{~K}$ at equal value of high voltage. Each specimen under investigation was treated by thermocycling (115 $\mathrm{K}$

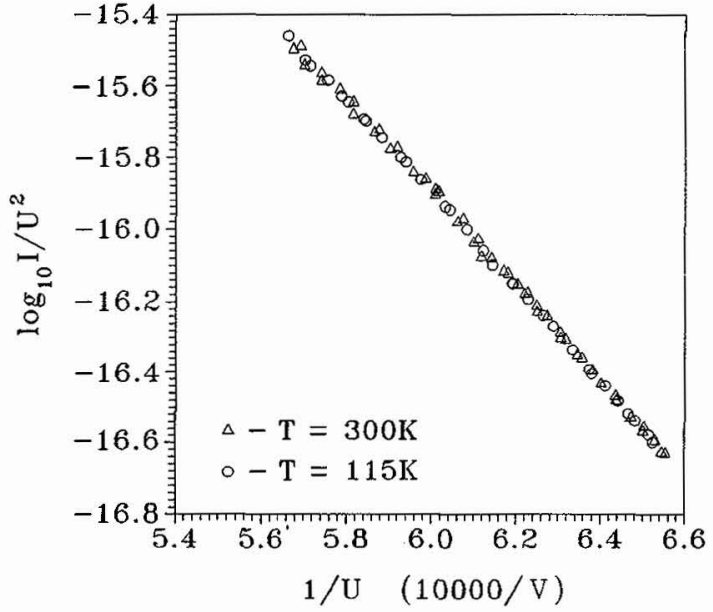

Fig.2. Current-voltage characteristic of emission current from field evaporated cleaned surface $\mathrm{YBa}_{2} \mathrm{Cu}_{3} \mathrm{O}_{6.9}$ single crystal specimen at 115 $\mathrm{K}$ (circles) and $300 \mathrm{~K}$ (triangles) on Fowler-Nordheim coordinates. and $300 \mathrm{~K}) 2-3$ times. The results of field emission measurements were stable and reproducible. The spectroscopy of $\mathrm{YBa}_{2} \mathrm{Cu}_{3} \mathrm{O}_{6.9}$ shows that cooling of the specimen resulted in increasing of the rate of increase at the Fermi edge of the electronic spectrum. Calculations based on a free electron model [3] show that this behaviour of TED's is typical of metals. Experiments made on a tungsten specimens have shown good agreement with these theoretical calculations. The metallic behaviour of $\mathrm{YBa}_{2} \mathrm{Cu}_{3} \mathrm{O}_{6.9}$ materials was revealed in photoemission experiments also [27]. The determination of the Fermi level $\left(\mathrm{E}_{\mathrm{F}}\right)$ at the high-energy edge of TED from $\mathrm{YBa}_{2} \mathrm{Cu}_{3} \mathrm{O}_{6.9}$ single crystals carried out in accordance with a 

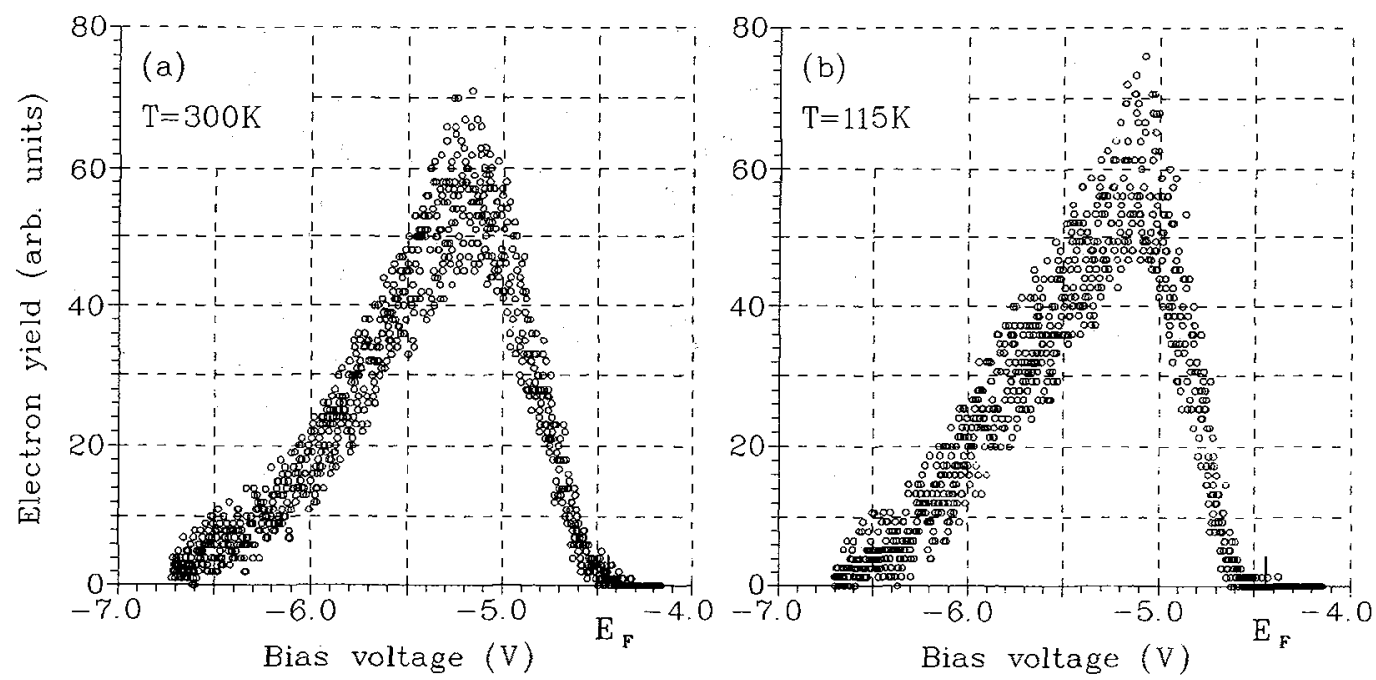

Fig.3. Field electron emission spectra from field evaporated cleaned surface $\mathrm{YBa}_{2} \mathrm{Cu}_{3} \mathrm{O}_{6.9}$ single crystal specimen at temperature $300 \mathrm{~K}$ (a) and that of the same specimen at $115 \mathrm{~K}$ (b) at the equal value of high voltage. ( $\left.\mathrm{E}_{\mathrm{F}}\right)$ - Fermi level of tungsten.

technique suggested in [28] gives the position of $E_{F} T E D$ at the level $0.67 \pm 0.14$ from maximum of the spectrum.

The theoretical fundamentals of using the field electron emission spectroscopy technique for the determination of the size of superconducting energy gap were worked out long before the discovery of HTSC materials [1,2]. A schematic diagram of the interface HTSC (in superconducting state) vacuum in a strong external electric field is shown in fig.4. The transition of the tip emitter from the

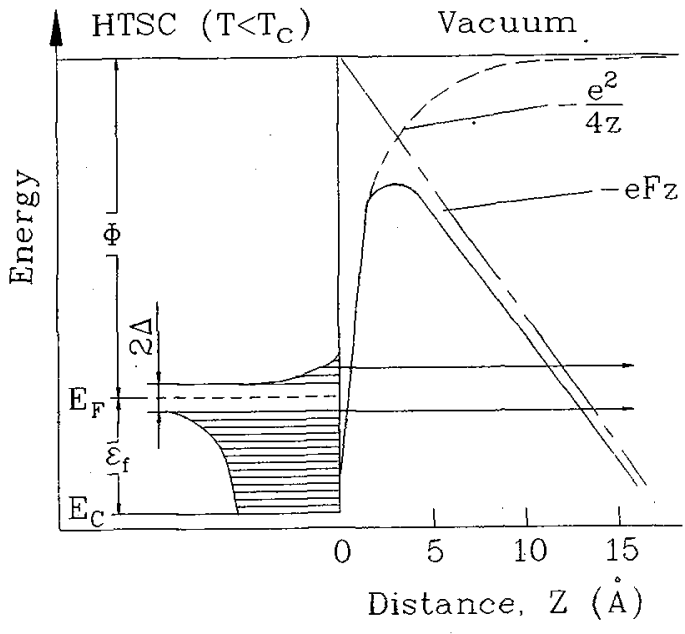

Fig.4. A schematic diagram of the interface HTSC (in superconducting state)- vacuum in a strong electric field. normal to superconducting state leads to the appearance of the superconducting gap in electronic energy spectrum $[1,2]$ and to a behaviour of the density of states near the gap of a following kind:

$$
N(E)=\frac{E}{\left(E^{2}-\Delta^{2}\right)^{1 / 2}}, \quad E>\Delta
$$

This means fall-through $2 \Delta$ wide near the Fermi level shows up in the field electron spectra in case of transition to the superconducting state. The small size of the gap in case of classical superconductors and limited energy resolution of existing analyzers [3] have not yet made it possible to observe superconducting energy gap at the electronic spectra from emitters which are in the in superconducting state. In the work presented a superconducting energy gap has been 

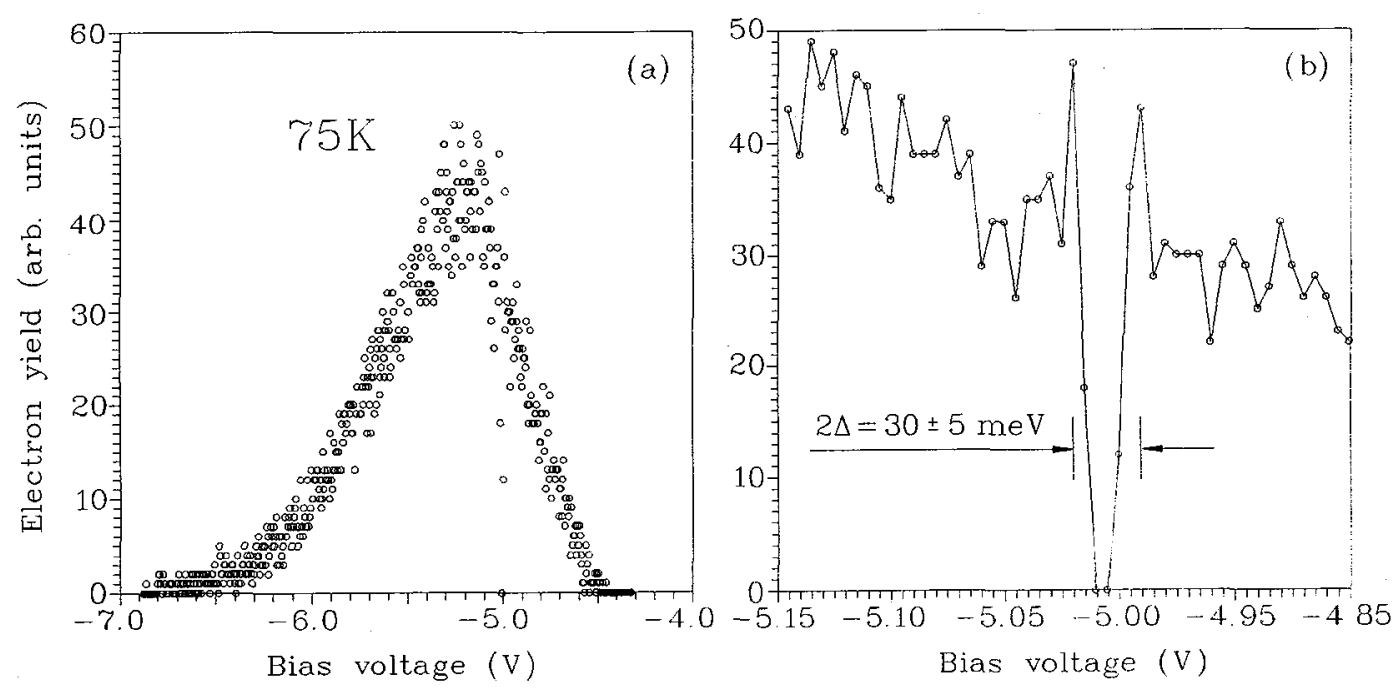

Fig.5. Field electron emission spectrum (a) from field evaporated cleaned surface $\mathrm{YBa}_{2} \mathrm{Cu}_{3} \mathrm{O}_{6.9}$ single crystal specimen which are in the superconducting state $(T=75 \mathrm{~K})$. (b) A section of the Fermi edge of the electronic spectrum measured at $75 \mathrm{~K}$ with superconducting energy gap.

visually registered for the first time by the FEES technique. A gap (fig.5) is revealed in the electron spectra from the atomically clean (100) plane of $\mathrm{YBa}_{2} \mathrm{Cu}_{3} \mathrm{O}_{6.9}$ single crystal specimen measured at 75 $\mathrm{K}$. The gap is found in the vicinity of 0.7 of maximum at the Fermi edge of the spectra, i.e. at the Fermi level. The limited energy resolution of the instrument ( $30 \mathrm{meV})$ leads to the smearing of the superconducting energy gap edges. Nevertheless, one can determine the value of the superconducting energy gap width for [100] orientation measured at $75 \mathrm{~K}$ as: $2 \Delta(75 \mathrm{~K})=30 \pm 5 \mathrm{meV}$. The value of $2 \Delta / k T_{c}$ referred to the absolute zero temperature is in this case equal to $2 \Delta(0) / k T_{c} \cong 4.7$, this being in good agreement with values obtained in tunnel experiments [29].

\section{CONCLUSIONS}

It is shown that in the total-energy distributions of field emitted electrons from HTSC emitters which are in the superconducting state a superconducting energy gap revealed. Investigations using FEES techniques make it possible to study the electronic properties of atomically clean (not depleted in oxygen) surfaces of HTSC materials and to determine the width of the superconducting energy gap with a high spatial resolution.

\section{Acknowledgments}

Authors would like to thanks Prof. G.A. Mesyats, Dr. V.F. Puchkarev and Prof. N.N. Syutkin for their support and attention to this work, Prof. R.Z Bakhtizin, Dr. Yu.M. Yumaguzin and S.N. Shilimanov for their help in device manufacturing, Dr. E.F. Talantsev for his advices during the experimental work. This research is partially supported by the State Committee on Science and Technology of Russia (grant No. 90179). 


\section{References}

[1] Gogadze G.A., Kulik I.O., Fiz. Met. Metalloved. (USSR) 23 (1967) 606-615.

[2] Gadzuk J.W., Surf. Sci. 15 (1969) 466-482.

[3] Gadzuk J.M., Plummer E.W., Rev. Mod. Phys. 45 (1973) 487-545.

[4] Ernst N., Schmidt W.A., Klein Ch., Melmed A.J., Larkins G.L., Physica C 213 (1993) 495-499.

[5] Muller E.W., Field Emission Microscopy, Adv. Electronics 3, No. 1 (Academic Press, New York, 1951).

[6] Muller E.W. and Tsong T.T., Field Ion Microscopy: Principles and Applications (Elsevier, New York, 1969).

[7] Modinos A., Field,Thermoionic and Secondary Electron Emission Spectroscopy (Plenum, New York, 1984).

[8] Kellog G.L., Brenner S.S., Appl. Phys. Lett. 51 (1987) 1851-1853.

[9] Melmed A.J., Shull R.D., Chiang C.K., Fowler H.A., Science 239 (1988) 176-178.

[10] Miller M.K., Melmed A.J., More K.L., J. Phys. (France) 49 (1988) C6-447-C6452.

[11] Mesyats G.A., Syutkin N.N., Ivchenko V.A., Talantsev E.F., J. Phys. (France) 49 (1988) C6-477 C6-481.

[12] Bakhtizin R.Z., Gotts S.S., Mesyats V.G., Shkuratov S.I., Yumaguzin Yu.M., Fiz. Met. Metalloved. (USSR) 67 (1989) 610-611.

[13] Shkuratov S.I., Mesyats V.G., Ivanov S.N., Yumaguzin Yu.M., Superconductivity (USSR) 3 (1990) 1214-1220.

[14] Shkuratov S.I., Surface Sci. 266 (1992) 88-99.

[15] Shkuratov S.I., Ivanov S.N., Shilimanov S.N., Surface Sci. 266 (1992) 224-231.

[16] Shkuratov S.I., Ivanov S.N., Shilimanov S.N., Physica C 213 (1993) 321-326.

[17] Ernst E., Schmidt W.A., Bozdech G., Naschitzki M., Melmed A.J., Surface Sci. 246 (1991) 183-188.

[18] Shkuratov S.I., Ivanov S.N., Shilimanov S.N., Instr. and Exp. Techn. 2 (1996) 1-9.

[19] Ivanov S.N., Shilimanov S.N., Shkuratov S.I., "Design of field electron emission spectrometer, field ion microscope and field electron emission microscope combination", Proc. XVI ISDEIV, Moscow-St.Petersburg, Russia, 23-30 May 1994, pp. 477-478.

[20] Bakhtizin R.Z., Field emission investigations of statistical processes in metals and semiconductors (Dr. Sc. Thesis, USSR, Ufa, 1989); Yumaguzin Yu.M., Energy Distribution of Field Emission Electrons from Tungsten at High Current Densities (Cand. Sc. Thesis, USSR, Ufa, 1988).

[21] Young R.D., Kuyatt C.E., Rev. Sci. Instr. 39 (1968) 1477-1480.

[22] Kostijlev V.A., Chebotaev N.M., Naumov S.V., Samokhvalov A.A., Superconductivity (USSR) 3 (1990) 2544-2552.

[23] Shkuratov S.I., Shilimanov S.N., Ivanov S.N., Supercond. Sci. Technol. 6(1993) 520-524.

[24] Miller M.K., More K.L., J. Phys. (France) 49 (1988) C6-483 - C6-488.

[25] Talantsev E.F., Supercond. Sci. Technol. 8 (1995) 593-604.

[26] Fischer R., Neumann H., Fortschr. Physik. 14 (1966) 603-692.

[27] Olson C.G., Liu R., Lynch D.W., Veal B.W., Chang Y.C., Jiang P.Z., Liu J.Z., Paulikas A.P., Arko A.J., List R.S., Physica C 162-164 (1989) 1697-1700.

[28] Shkuratov S.I., Physica C 230 (1994) 283-291.

[29] Bentum P.J.M., Kempen H., Scanning Tunneling Microscopy 20 (1992) 207-242. 